\title{
Optimising sustainability at an urban level: a case study of Dubai Sustainable City
}

\author{
N. El-Bana, S. E. Selim \& H. Taleb \\ British University in Dubai, UAE
}

\begin{abstract}
With the growing interest in sustainability and sustainable design both regionally and globally, there emerged the challenge of designing and constructing a sustainable community in the desert, which invited some interesting ideas. One of these was Dubai Sustainable City, with climate and environment influencing its design. The UAE and Dubai in particular are trying to set a reference benchmark when it comes to sustainable design in such harsh climates. The aim of this study is to assess a sample case study of a new sustainable urban settlement from this region (Dubai Sustainable City) through a comparative analytical study of the chosen project (Dubai Sustainable City), a comparative study (assessment: LEED) which is held between the existing design and the same - but yet enhanced - design after applying the research recommendations. Some of the points that were raised - besides the sustainability of the design itself - through a practical approach were health, social life and the liveability of the current project design. Whilst this paper mainly focuses on the UAE's sustainable developments, it could be argued that many of the research outcomes are of relevance to other countries and regions, especially those with the same social and harsh environmental conditions as the UAE.

Keywords: sustainability, design strategies, land use, adjustments capacity, transportation, sustainable landscape, CityCAD, master planning, sustainable communities, urban design.
\end{abstract}

\section{Introduction}

Architecture is an intensive experience of complexity, elements, strength, joy, concepts, expressions, structures and mechanical designs, always complex and 
contradicting and working on a macro scale of urban design adds to the difficulties [1].

Sustainability is today's major global concern and comes from a global instinct for survival. First, and of huge importance, are the three-Rs' strategies: Reduce, Reuse and Recycle. Urban communities contribute in terms of resource consumption in the sense that they are a group of individual buildings where people live and interact in - and with - waste production. This is where there is a necessity that architecture and urban design must offer solutions for human beings to sustain living. This study takes the realistic approach of case study analysis of Dubai Sustainable City and analysis of existing site data. It is divided into three stages: understanding (analysis of existing conditions); exploring (documenting the charrette and filling materials) and deciding (preparation and presentation of the report). The feasibility of future guidelines for greater sustainability will take the outcomes to the next level of retrofitting and enhance the current project's urban sustainability.

\section{Literature review}

The current environmental crisis, declining resources, economic uncertainty, increased population and global urbanization is propelling the world towards sustainability as a necessity. The idea of sustaining a way of life or economic and social wellbeing is as old as humanity. What is new in the idea is scientific knowledge that our planet's humanly habitable space is shrinking and that stable ecosystems and biodiversity are under threat from both global climate change and human activity. Human perception does not yet seem to have recognized the enormity of these problems as the parts affect the whole in a co-evolutionary synergy. Concentrated urban populations draw heavily on water, energy and other resources, while producing equally heavy amounts of waste. This should be considered in relation to larger concepts of sustainability, including equitability and ecological concerns [2].

Other definitions point to seeing the world as a system that connects space, place, and time within a single interconnected planet. Therefore, big changes are needed immediately, but still remain more ideals than realities [3].

Other elements of architectural and urban environments - such as public spectacle - are discussed in Venturi's second influential book Learning from Las Vegas [4] and may have challenged public acceptance of sustainability, but under very different circumstances. Today, despite the continued popularity of Disneyland, Dubai land and Las Vegas, the city of spectacle must consider how to maintain urban attractions while reducing costs and consumption of water and energy and production of waste [2]. Urban spaces and individual buildings contribute enormously to resource consumption and waste production. 


\section{Methodology}

\subsection{Design methodology and approach}

This paper combines a literature review, site visit and analysis. Empirical data was collected through interviews with key personnel and data from developers. Formal, structural and technical design elements were examined, compared and contrasted in a comparative analytical study. The intention was to establish a foundation for the restructuring of the current Dubai Sustainable City.

Various properties were summed up using CityCAD, discussed and concluded in order to determine the basis of a sustainable community. These included land use, roads and infrastructure, building materials, landscape and vegetation, accessibility, a car free environment, renewable energy implementation and social sustainability.

\section{Case study}

\subsection{Location}

Dubai Sustainable City is located in a remarkable location; it is 15 minutes from downtown Dubai, 20 minutes from Dubai International Airport, and10 minutes from Al-Makttoum airport and the World Expo 2020 Location (Diamond Developers, 2014).

\subsection{Existing design}

Dubai Sustainable City's designers aimed to present to Dubai a project of a kind that adopted sustainable urban design settings, making this city a regional leader in eco-tourism alongside environmental protection and awareness. It features 500 townhouses and villas, an eco-resort and environmental design institute, all of which are served with a wide range of facilities and occupies almost 46 hectares of land. The city is designed to accommodate 2,700 residents along with a daily population of 6,000 , producing $10 \mathrm{MW}$ peak solar production of energy as well as supplying all its residents with organic food from its farms and bio domes. Residents will use their private vehicles on a ring road surrounding the city to centrally located, PV covered, parking lots that are 90 meters walkable distance from the furthest villa; from there they can walk or take the electric carts provided by the city itself (Diamond Developers, 2014).

\subsection{Analysis}

\subsubsection{Overview of existing design}

Total built up area

$0.44 \mathrm{sq} \mathrm{km}$

Total green space

$0.07 \mathrm{sq} \mathrm{km}$

Estimated population
5203

Total energy use

$23288 \mathrm{kWh} /$ day

(8500000 kWh/year)

Total parking spaces 3025 total 
Vehicle trips 585/day

Residential GFA 68037sqm

Number of dwellings $\quad 530$

Residential population 2863

Office GFA 13333 sqm

\subsubsection{Land use summary}

Shops (A1)

Financial/professional services (A2)

Restaurants and cafes (A3)

Hot food takeaways (A5)

Business (B1)

Storage and distribution (B8)

Hotels (C1)

Dwellings (C3)

Health service (D1)

School (D1)

Other institutions (D1)

Assembly and leisure (D2)

Other use

Semi-detached or detached housing

Open space - playground

Open space - sports and recreation

Open space - park

Open space - managed green area

Open space - car park
Retail GFA $\quad 87194$ sqm

No. of shops $\quad 50$

Other GFA 239991 sqm

$\begin{array}{ll}39627 & \text { sqm }(9.7 \%) \\ 528 & \text { sqm }(0.13 \%) \\ 6235 & \text { sqm }(1.53 \%) \\ 1056 & \text { sqm }(0.26 \%) \\ 13333 & \text { sqm }(3.26 \%) \\ 528 & \text { sqm }(0.13 \%) \\ 25893 & \text { sqm }(6.34 \%) \\ 10563 & \text { sqm }(2.59 \%) \\ 1866 & \text { sqm }(0.46 \%) \\ 23487 & \text { sqm }(5.75 \%) \\ 66265 & \text { sqm }(16.22 \%) \\ 6563 & \text { sqm }(1.61 \%) \\ 5449 & \text { sqm }(1.33 \%) \\ 57474 & \text { sqm }(14.07 \%) \\ 3185 & \text { sqm }(0.78 \%) \\ 21310 & \text { sqm }(5.22 \%) \\ 4319 & \text { sqm }(1.06 \%) \\ 66417 & \text { sqm }(16.26 \%) \\ 54455 & \text { sqm }(13.33 \%)\end{array}$

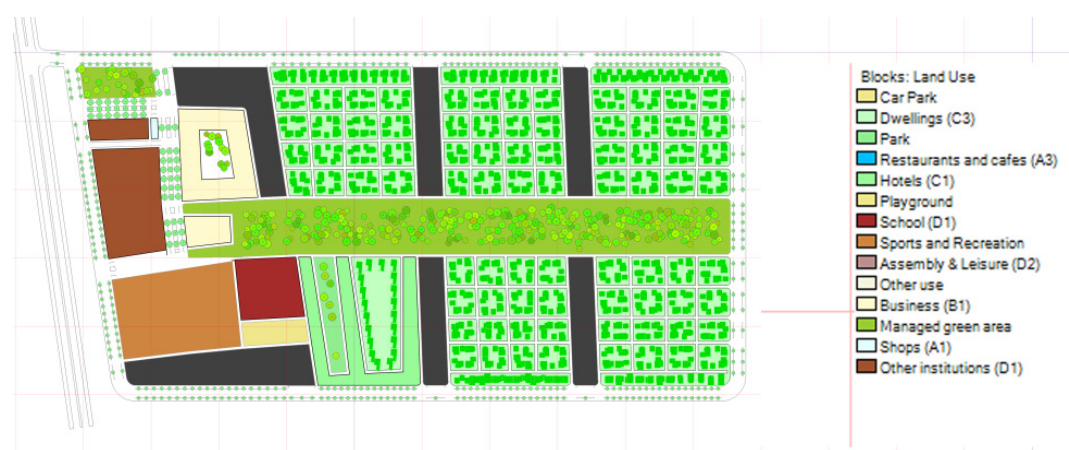

Figure 1: Land use analysis (CityCAD).

\subsubsection{Residential summary}

Semi-detached or detached housing $\quad 530$ units

Total:

530 units

Total residential units (existing group) 530 


\subsubsection{Liveability analysis}

Net residential density

Residential population density

Average dwelling size

Average habitable room size

Approximate public realm density

School provision

Green space per person

Total number of trees
$1500.79 \mathrm{dw} / \mathrm{sq} \mathrm{km}$

$8104.26 \mathrm{ppl} / \mathrm{sq} \mathrm{km}$

$128.31 \mathrm{sqm}$

$31.63 \mathrm{sqm}$

$28.69 \mathrm{sqm} /$ person

2340 spaces

$14 \mathrm{sqm} /$ person

482

Average number of parking spaces within 5-mins walk

Average number of parking spaces per residential population

Average population per entrance

$32 \mathrm{ppl} /$ entrance

Average distance from dwellings to:

$\begin{array}{llll}\text { Green space } & 96 \mathrm{~m} & \text { Convenience store } & 423 \mathrm{~m} \\ \text { Health service } & 369 \mathrm{~m} & \text { Bank } & 423 \mathrm{~m} \\ \text { Education } & 382 \mathrm{~m} & \text { Pharmacy } & 423 \mathrm{~m} \\ \text { Parking space } & 75 \mathrm{~m} & \text { Supermarket } & 423 \mathrm{~m} \\ \text { Shops } & 244 \mathrm{~m} & & \end{array}$

\subsubsection{Movement information}

Cycle lanes

Bus lanes

Accessibility (pedestrian net. less than 1:20)

Estimated $\mathrm{CO}_{2}$ from daily trip generation

Daily vehicle trips

Total parking spaces

Total parking spaces required

Net parking spaces
$0 \mathrm{~km}(0 \%$ of street network)

$2.94 \mathrm{~km}(18.17 \%$ of street network)

$100 \%$

$0 \mathrm{~kg} /$ year

585

3025

530

2495

\subsection{Decisions}

Findings and the hypothesis arising from analysis shows the need for using mixed sustainability theory and practice, with integration of the technical, economic and social and design elements. New large-scale project design and construction projects must follow stringent sustainability regulations, while smaller units remain exempted and retrofitting has not yet been regulated. Moreover, the forthcoming approach of redesigning and improvement to the Dubai Sustainable City intends to describe how the surroundings urban context can work together with the Dubai Sustainable City project and be integrated in harmony with the project's urban context. The intention is to be beneficial and implement sustainability in a step-by-step way, leading to an integrated urban system.

\section{Strategies}

The main strategies and points approached by this study are enhancing the urban sustainability of the case study. A car free community should be introduced, after 
proposing convenient and clean methods of transportation in the community. Cycling facilities should be integrated with dedicated routes and storage. Street sections should be identified on the basis of providing people with a walk able community via shaded pedestrian routes). A change in the orientation of blocks will offer better air quality and ventilation purposes and offer recreational space - a public realm - on both block and neighborhood bases to enhance the social experience and sustainability. Reducing the parking footprint and increasing green areas is also vital, as is enhancing the moveability and service hierarchy.

\section{Results}

\subsection{Project access}

The case study design is based on a gated community with one exit and entrance. According to LEED, sustainable community should not be gated as it should be well connected to the surrounding urban context.

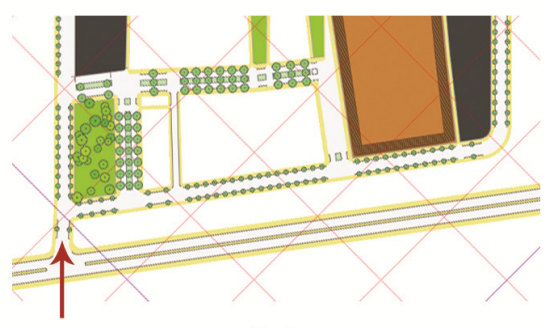

Before

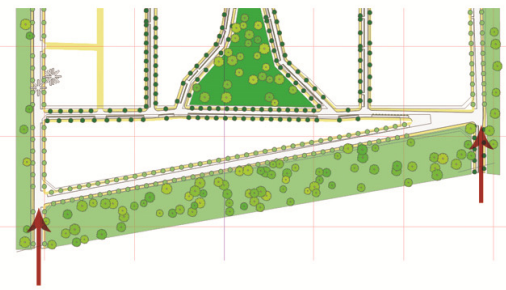

After

Figure 2: Case study entrances from the main road before and after redesign (source: authors).

\subsection{Orientation}

In order to enhance the wind flow and air quality throughout the case study, a block orientation change is proposed as a strategy allowing more airflow through
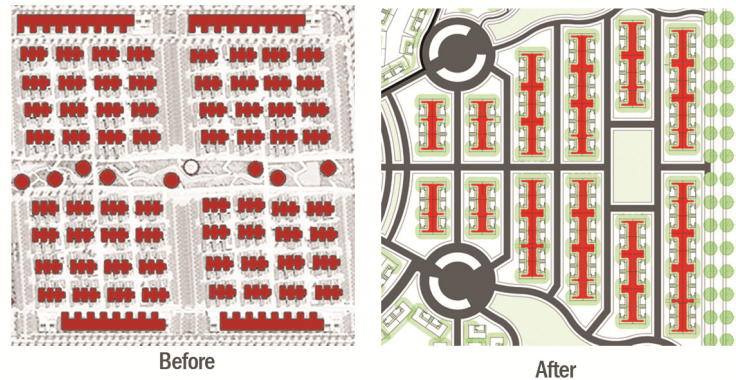

Figure 3: Block orientation before and after redesign (source: authors). 
the urban tissue and enhancing the air quality. Changing the block orientation will involve it facing the favored wind direction with the long side of the block preventing the favored wind from passing through the back side of the block to being parallel to it. This will enhance the air quality and airflow through the urban tissue by channeling the wind in the desired direction.

- Flow design analysis

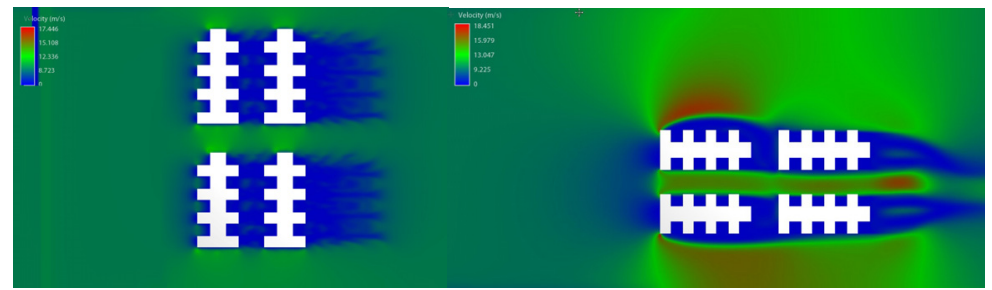

Figure 4: Air velocity simulation before and after re-orientation (authors).

\subsection{Variety}

The existing design of the case study only contains one type of residential unit; detached villas with two main sizes 300 sqm and 500 sqm. This gives little chance for variety and social interaction between the different classes, so a strategy aiming to enhance the performance of the urban design is that a multistorey zone is added to the community containing a variety of apartments beside the detached and semi-detached villas. This will have the effect of providing the community with a broad line of social interaction and social sustainability.

Residential units - existing group

Dwellings - studio flats (C3)

Dwellings - cluster flats (C3)

Semi-detached or detached housing

Total:

Total residential units (existing group)

266 units

84 units

304 units

654 units

735

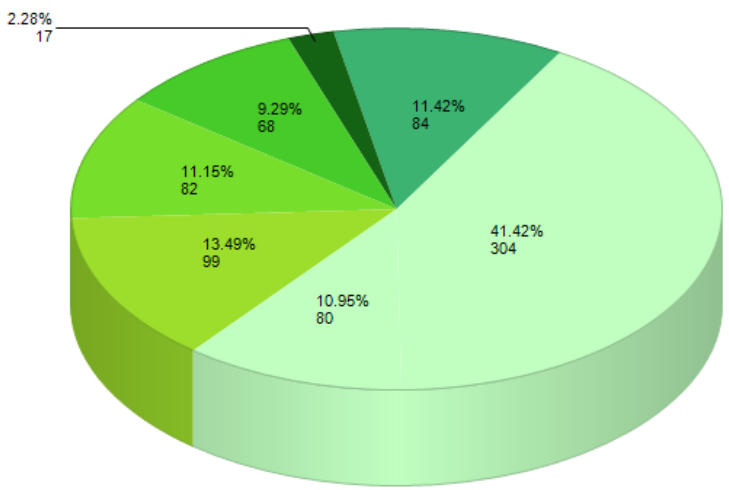

$\square$ Semi-detached or Detached Housing

$\square$ Dwellings (C3)

$\square$ Dwellings - studio flats (C3)

$\square$ Dwellings - 1-bed flats (C3)

$\square$ Dwellings - 2-bed flats (C3)

$\square$ Dwellings - 4-bed flats ( $\mathrm{C} 3$ )

$\square$ Dwellings - Cluster Flats (C3)

Figure 5: Residential analysis (modified design) (source: CityCAD). 


\subsection{Car free community}

In order to achieve the goal of a livable car free community, it is essential to prevent fossil fuel cars from entering the heart of Dubai Sustainable City. Therefore, several strategies and transportation means have to be implemented.

- Centralized underground parking

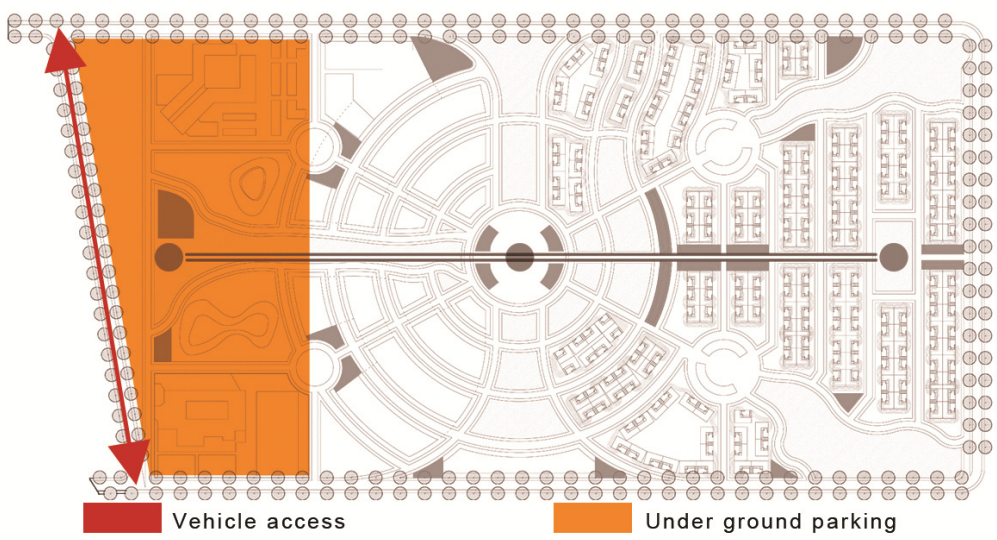

Figure 6: Underground parking and vehicle access (source: authors).

CityCAD parking analysis:

Vehicle parking:

Total parking spaces

Total parking spaces required

Net parking spaces

Average number of parking spaces within 5-mins walk Average number of parking spaces per residential population 2.56 Average population per entrance 46 people/entrance

\subsection{Service hierarchy}

Studying the case study master plan for services distribution, all services are concentrated at street elevation, providing services only to residents, as this is a gated community. All services are on one layer only, some as far as 1000 meters from some residents.

Aiming to enhance the livability of the case study as a major part of creating a sustainable community, several layers of service have to be introduced as following:

- Urban context layer: providing service to the case study as well as to nearby future urban developments in this newly developed area of the city. Examples include district cooling, school, hospital, Mosque, shopping areas, restaurants and convenience stores. 
- Case study context: providing services to the community within the case study. Examples include school, community centre, sports, playgrounds, shops and gathering areas.

- Neighborhoods context: providing services for the neighborhoods such as a clinic, shop, playground and cafe).

- CityCAD livability analysis after modification:

- Average distance from dwellings to:

$\begin{array}{ll}\text { Green space } & 63 \mathrm{~m} \\ \text { Health service } & 114 \mathrm{~m} \\ \text { Education } & 363 \mathrm{~m} \\ \text { Parking space } & 286 \mathrm{~m} \\ \text { Shops } & 52 \mathrm{~m} \\ \text { General/convenience store } & 148 \mathrm{~m} \\ \text { Bank } & 384 \mathrm{~m} \\ \text { Pharmacy } & 384 \mathrm{~m} \\ \text { Supermarket } & 160 \mathrm{~m}\end{array}$

\subsection{Moveability}

Enhancing the performance of case study moveability requires the implementation of shaded walkable roads if a shading device is introduced that provides shade as well as energy and ventilation.

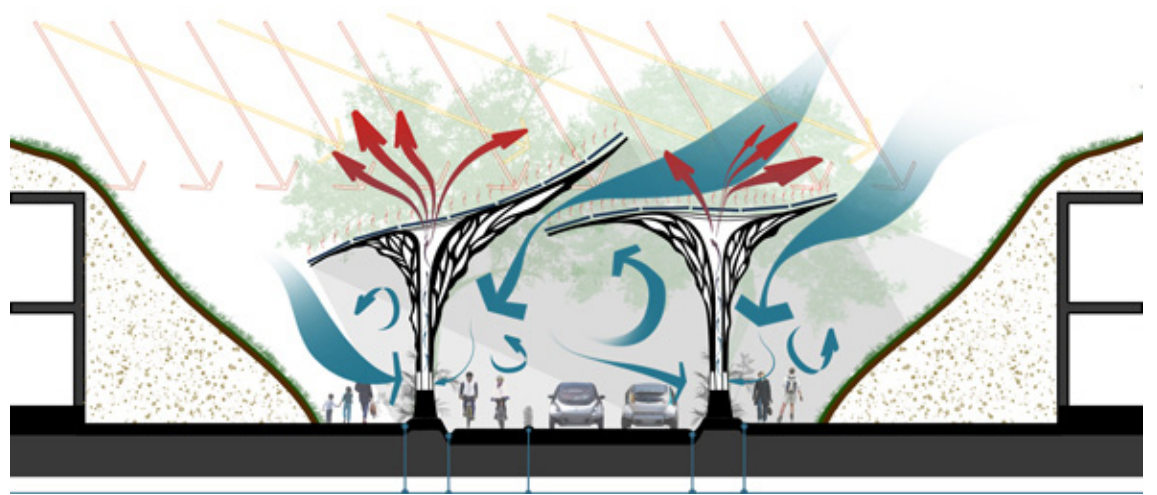

Figure 7: Streetscape and description of a new element increasing street walkability (authors).

A permeable master plan will see defined landmarks to guide people. 


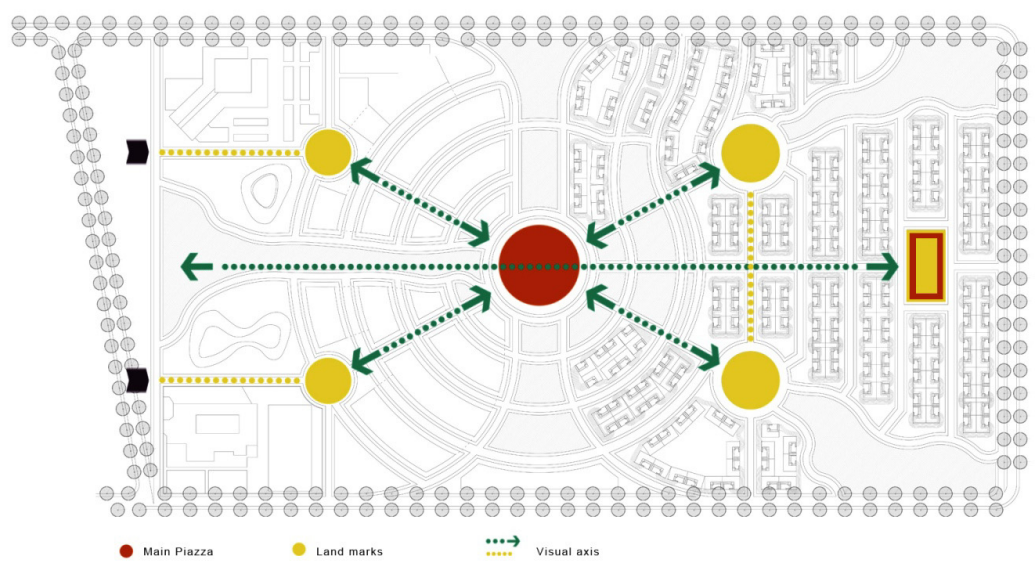

Figure 8: Main landmarks and visual axis (source: authors).

\section{Conclusion}

Throughout the proposed strategies observed through software analysis and simulation as well as previous reference, the design has been improved in several aspects. This is especially true in terms of the social and livability aspects, putting this project a step ahead towards building and developing a sustainable community.

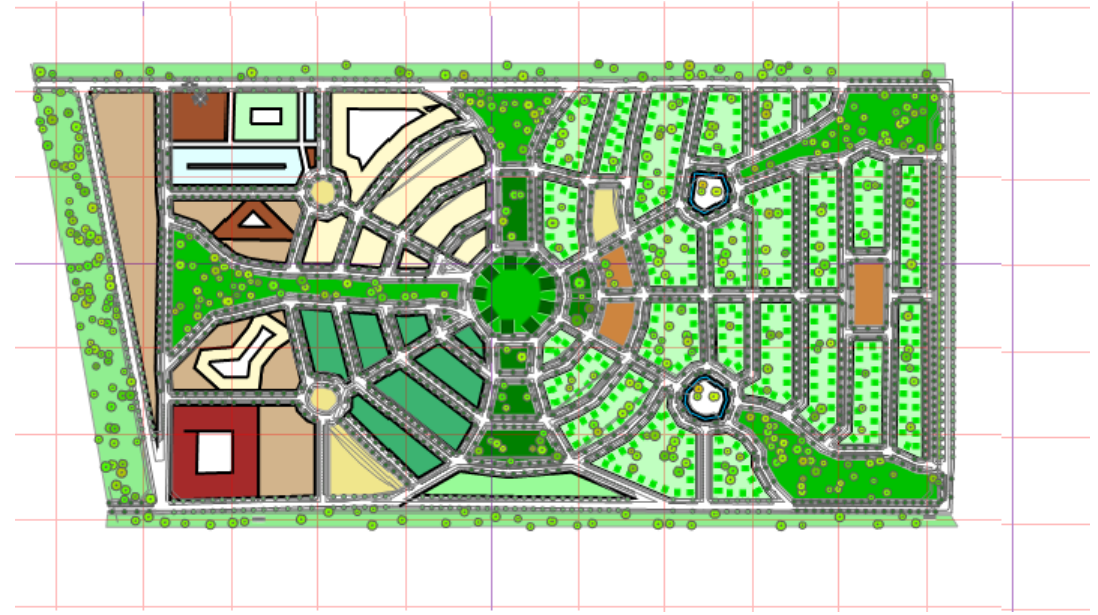

Figure 9: Master plan after applying the enhancement strategies (source: CityCAD). 


\section{Acknowledgement}

The authors would like to thank "MUSTADAMA Ltd. Sustainable Solutions" in Masdar City, Abu Dhabi for sponsoring this paper.

\section{References}

[1] Venturi, R., Complexity and contradiction in Architecture, MOMA Press: Newyork, 1966.

[2] Wheeler, S., Planning for sustainability: Creating Liveable, Equitable and Ecological Communities, Routledge: London, 2013.

[3] Graham, P., P. B., Guidlines on education policy for sustainable built environment, UNEP: Nairobi, Kenya, 2010.

[4] Venturi, R., Learning From Las Vegas, The MIT Press: Cambridge London, 1972. 